\title{
Cytoplasmic pH Regulation and Chloride/Bicarbonate Exchange in Avian Osteoclasts
}

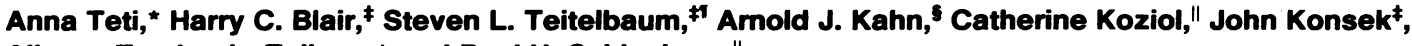 \\ Alberta Zambonin-Zallone, ${ }^{*}$ and Paul H. Schlesinger" \\ *Institute of Human Anatomy, University of Bari Medical School, Bari, Italy; ${ }^{\ddagger}$ Department of Pathology and Laboratory Medicine, \\ Jewish Hospital at Washington University Medical Center, St. Louis, Missouri, 63110; ${ }^{\$}$ Pediatric Research Institute, St. Louis \\ University Medical Center, St. Louis, Missouri, 63110; "Department of Biomedical Research, Washington University School of Dental \\ Medicine, St. Louis, Missouri, 63110; and 'Shriner's Hospital for Crippled Children (St. Louis Unit), St. Louis, Missouri 63131
}

\begin{abstract}
Osteoclasts resorb bone by first attaching to the bone surface and then secreting protons into an isolated extracellular compartment formed at the cell-bone attachment site. This secretion of protons (local acidification) is required to solubilize bone hydroxyapatite crystals and for activity of bone collagendegrading acid proteases. However, the large quantity of protons required, $2 \mathrm{~mol} / \mathrm{mol}$ of calcium, would result in an equal accumulation of cytosolic base equivalents. This alkaline load must be corrected to maintain cytosolic $\mathrm{pH}$ within physiologic limits. In this study, we have measured cytoplasmic pH with pH-sensitive fluorescent compounds, while varying the extracellular ionic composition of the medium, to determine the nature of the compensatory mechanism used by osteoclasts during bone resorption.

Our data show that osteoclasts possess a chloride/bicarbonate exchanger that enables them to maintain normal intracellular $\mathrm{pH}$ in the face of a significant proton efflux. This conclusion follows from the demonstration of a dramatic cytoplasmic acidification when osteoclasts that have been incubated in bicarbonate-containing medium are transferred into bicarbonate-free medium. This acidification is absolutely dependent on and proportional to medium $\left[\mathrm{Cl}^{-}\right]$. Furthermore, acidification is inhibited by the classic inhibitor of red cell anion exchange, 4,4'-diisothiocyanatostilbene-2,2'-disulfonate, and by diphenylamine-2-carboxylate, an inhibitor of chloride specific channels. However, the acidification process is neither energy nor sodium dependent. The physiologic importance of chloride/bicarbonate exchange is demonstrated by the chloride dependence of recovery from an endogenous or exogenous alkaline load in osteoclasts. We conclude that chloride/bicarbonate exchange is in large part responsible for cytoplasmic pH homeostasis of active osteoclasts, showing that these cells are similar to renal tubular epithelial cells in their regulation of intracellular pH.
\end{abstract}

\section{Introduction}

The remodeling of the vertebrate skeleton is a precisely regulated process in which the needs of calcium homeostasis must

Address reprint requests to Dr. Paul Schlesinger, Department of Biomedical Research, Washington University School of Dental Medicine, 4559 Scott Avenue, St. Louis, MO 63110.

Received for publication 31 July 1987 and in revised form $23 \mathrm{Au}$ gust 1988.

J. Clin. Invest.

(c) The American Society for Clinical Investigation, Inc.

$0021-9738 / 89 / 01 / 0227 / 07 \quad \$ 2.00$

Volume 83, January 1989, 227-233 be balanced against the site-specific requirements of mechanical support. To achieve such precise regulation, the principal bone-resorbing cell, the osteoclast, forms an extracellular compartment between itself and the bone surface that segregates resorptive activity from the surrounding milieu. This compartment consists of a region of highly folded plasma membrane (the ruffled membrane) surrounded by an actinrich clear zone that serves to bind the osteoclast to the bone surface $(1,2)$. The interior of the resorptive compartment is actively acidified to $\mathrm{pH} \sim 5(3-5)$, despite the fact that solubilization of bone mineral, calcium hydroxyapatite $\left(\mathrm{Ca}_{3}\left(\mathrm{PO}_{4}\right)_{2}\right.$ $\left.\mathrm{Ca}(\mathrm{OH})_{2}\right)$, consumes two moles of protons for each mol of $\mathrm{Ca}^{2+}$ produced. This acidic environment also favors the lytic activity of collagen-degrading acid proteases (6-11). The acidification of this compartment has been attributed to an electrogenic vacuolar $F_{1} F_{0}$-like proton pump located on the ruffled membrane (12). By inference, the activity of this pump must be substantial because, $6 \mathrm{~mol} \mathrm{H} /$ mol hydroxyapatite are consumed in crystal solubilization at $\mathrm{pH} 5$, and the peptides and amino acids released as a consequence of proteolytic degradation of bone matrix proteins will buffer the bone resorbing space.

Active proton secretion, by any cell, generates an equal load of cytoplasmic base equivalents, principally as $\mathrm{HCO}_{3}^{-}$ under physiological conditions. For example, in the renal tubule, an electrogenic pump transports protons into the tubular lumen (13-15), and a chloride-bicarbonate exchanger in the basolateral membrane prevents intracellular alkalinization by exporting base equivalents as bicarbonate (16-19). The importance of this mechanism is underscored by the inability of renal tubular cells to secrete protons when anion exchange is blocked (17). In this study, we document that the active osteoclast displays the exchange of intracellular bicarbonate for extracellular chloride. When this process is inhibited by reducing extracellular chloride, the osteoclast is unable to maintain its normal intracellular pH. Hence, the osteoclast, like the renal tubular cell, both secretes protons and compensates for cytoplasmic alkalinization by $\mathrm{a} \mathrm{Cl}^{-} / \mathrm{HCO}_{3}^{-}$exchange mechanism.

\section{Methods}

\section{Materials}

Chemicals were purchased from Sigma Chemical Co., St. Louis, MO, except as noted.

\section{Experimental procedures}

Osteoclast isolation. Osteoclasts were isolated from the medullary bone of laying hens as described by Zambonin-Zallone et al., and modified by Blair et al. $(12,13)$. Briefly, mature laying hens (Gallus domesticus), fed a low calcium diet for $3 \mathrm{wk}$, were killed by inhalation anesthesia overdose, and the femora and tibiae were removed, split, 
Table I. Experimental Conditions Used For Intracellular pH Measurement in Osteoclasts

\begin{tabular}{|c|c|c|c|c|c|}
\hline \multirow[b]{3}{*}{ Ester } & \multicolumn{2}{|c|}{$\begin{array}{l}\text { Dye-loading } \\
\text { parameters }\end{array}$} & \multicolumn{3}{|c|}{ Fluorescence parameters } \\
\hline & & & \multicolumn{2}{|c|}{ Excitation } & \multirow[b]{2}{*}{ Emission } \\
\hline & $\begin{array}{l}\text { Concen- } \\
\text { tration }\end{array}$ & Time & Upper & Lower & \\
\hline & $\mu M$ & $\min$ & $n m$ & $n m$ & $n m$ \\
\hline Carboxyfluorescein diacetate & 100 & 30 & $495^{*}$ & $450^{*}$ & $519^{*}$ \\
\hline BCECF-AM & 5 & 180 & $470^{\ddagger}$ & $503^{\ddagger}$ & $530^{\ddagger}$ \\
\hline
\end{tabular}

Dye loading was performed at $37^{\circ} \mathrm{C}$ in $140 \mathrm{mM} \mathrm{NaCl}, 10 \mathrm{mM}$

Hepes, pH 7.4 .

* Values from Thomas et al. (15).

\# Values have been modified from those of Rink, Tsien, and Pozzan

(16) to account for narrow-band excitation curves that showed that the excitation maximum frequency shifts down by $\sim 10 \mathrm{~nm}$ at $\mathrm{pH}$ above the isobestic point, resulting in a paradoxical decrease in emission ratio at high $\mathrm{pH}$. By using an excitation frequency that is on the up-slope of this excitation peak throughout the $\mathrm{pH}$ range, a uniform increase in emission ratio is obtained with increasing $\mathrm{pH}$ in the useful range of the dye (see Fig. 2).

and washed with cold PBS. At $4^{\circ} \mathrm{C}$, the medullary bone was excised and pressed through a $100-\mu \mathrm{m}$ nylon sieve, resulting in a cell suspension rich in osteoclasts. Osmotic shock with $0.2 \% \mathrm{NaCl}$ was used to lyse red cells. The cell suspension was sedimented for $1 \mathrm{~h}$ at unit gravity through $70 \%$ heat-inactivated FCS/30\% PBS, and the sediment, enriched in osteoclasts (from $6 \times 10^{6}$ to $15 \times 10^{6}$ per animal) was plated at 20,000 cells $/ \mathrm{cm}^{2}$ with $1 \mathrm{mg}$ of $25-50 \mu \mathrm{m}$ devitalized bone particles (21) per $10^{6}$ osteoclasts, in MEM containing $10 \% \mathrm{FCS}$ and 3 $\mu \mathrm{g} / \mathrm{ml}$ cytosine-1-beta-D-arabinofuranoside. After $24 \mathrm{~h}$ at $37^{\circ} \mathrm{C}$ in $5 \%$ $\mathrm{CO}_{2}$, viable osteoclasts, adherent to the bone particles, were suspended by gentle washing, sedimented twice in PBS for $20 \mathrm{~min}$ to separate osteoclast-bone particle aggregates from floating cells, and plated $\left(\sim 20,000 / \mathrm{cm}^{2}\right)$ on nitric acid washed glass slides $(2 \times 0.8 \times 0.2 \mathrm{~cm}$, referred to below as chips). The osteoclasts ( $\sim 90-95 \%$ pure) were used for the experiments from the third to the sixth day of culture.

Intracellular $\mathrm{pH}$ measurement. The intracellular $\mathrm{pH}$ was determined using the fluorometric technique described by Thomas et al. (22). Using this method, the cells are exposed to a membrane-permeant ester of a $\mathrm{pH}$-sensitive fluorophore. The $\mathrm{pH}$ probe in its esterified form diffuses into the cell, where esterases produce a hydrophilic, impermeant form of the fluorophore (see Fig. 1). The conditions used for loading the cells and the wavelengths for $\mathrm{pH}$ measurement are stated in Table I. 6-carboxyfluorescein $\left(\mathrm{p} K_{\mathrm{a}} \sim 6\right)$ was used initially for intracellular $\mathrm{pH}$ measurements, which is an adequate method for detection of major shifts from pH 7 ( $\sim 0.5 \mathrm{U})$. However, $2^{\prime}, 7^{\prime}$-bis-(2-carboxyethyl)-5-carboxyfluorescein, tetraacetoxymethyl ester (BCECF) ${ }^{1}$ was used in some determinations because it allows more accurate $\mathrm{pH}$ measurements in the studied range (6.5-7.4) with its $\mathrm{pK}_{\mathrm{a}}$ of $\sim 7$. After incubation with either dye, the cells were washed three times with PBS to remove extracellular fluorophore. Leakage of the dye from osteoclasts was sufficiently slow $(\sim 1 \% /$ minute $)$ to allow accurate $\mathrm{pH}$ measurements for $60 \mathrm{~min}$

The fluorescence was monitored using an Aminco SPF 500 ratio spectrofluorometer (Silver Springs, MD) equipped with a temperature-controlled water jacket set at $37^{\circ} \mathrm{C}$. For fluorescent spectroscopy, the chips were mounted in a holder designed to fit securely into a

1. Abbreviations used in this paper: BCECF-AM, 2',7'-bis-(2-carboxyethyl)-5-carboxyfluorescein, tetraacetoxymethyl ester; DIDS, 4,4'-diisothiocyanatostilbene-2,2'-disulfonate; DIPH, diphenylamine-2-carboxylate.

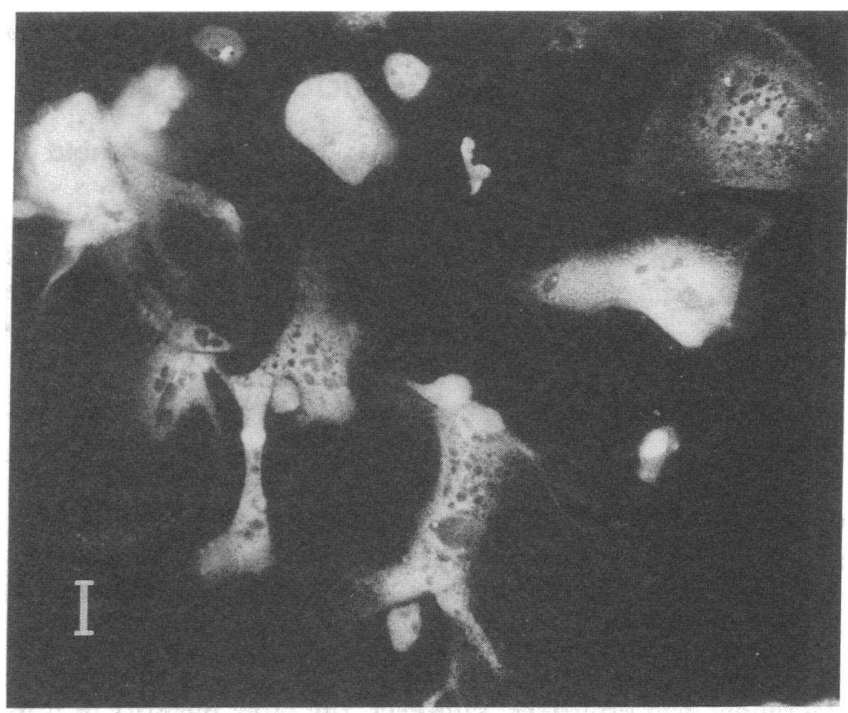

Figure 1. Fluorescence photomicrograph of osteoclasts loaded with 6-carboxyfluorescein diacetate. This compound, a membrane permeant dye, is deesterified in the cytoplasm forming membrane-impermeant, $\mathrm{pH}$ sensitive 6-carboxyfluorescein. Note that the dye is uniformly distributed in the cytoplasm and is not concentrated in intracellular organelles. $\times 500$. Bar, $10 \mu \mathrm{m}$.

standard spectrophotometer cuvette and to hold the cells at the optimal angle of $49^{\circ}$ to the exciting light beam, to minimize light scattering and diffraction into the detector (23). The chips were transferred from cuvette to cuvette while mounted in the holder; such transfers and initial readings took 20-30 s. All experiments were performed at least three times with different osteoclast preparations.

Media used for dye loading and $\mathrm{pH}$ determinations were based on

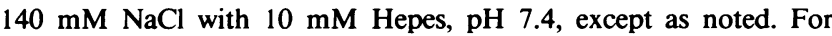
incubations in media containing bicarbonate, $25 \mathrm{mM} \mathrm{NaHCO}$ was added to this salt solution, and the $\mathrm{pH}$ was adjusted to 7.4 immediately before it was applied to the cells. The energy dependence of osteoclastic intracellular $\mathrm{pH}$ regulation and of the effect of bicarbonate on cytoplasmic $\mathrm{pH}$ was determined by including $5 \mathrm{mM}$ 2-deoxyglucose and $2.5 \mathrm{mM} \mathrm{KCN}$ in all the solutions.

Standard curves. Standard curves relating $\mathrm{pH}$ and fluorescence excitation ratios were obtained by placing the cells in medium containing $130 \mathrm{mM} \mathrm{KCl}, 20 \mathrm{mM} \mathrm{NaCl}, 5 \mathrm{mM}$ Hepes, and the $\mathrm{K}^{+} / \mathrm{H}^{+}$ ionophore nigericin $(10 \mu \mathrm{g} / \mathrm{ml})$. The $\mathrm{pH}$ of this medium was varied in steps from 8.0 to 4.0 using $\mathrm{NH}_{4} \mathrm{OH}$ or acetic acid, and fluorescence emission upon excitation at the two wavelengths was determined at each $\mathrm{pH}$. The cells were allowed to equilibrate at each $\mathrm{pH}$ until the ratio did not change for $10 \mathrm{~min}$. These ratios were then fitted to a function that describes the relationship between fluorescence ratio and pH $(24,25)$ : ratio $=P_{1}\left[\mathrm{H}^{+}\right]-P_{2} K_{\text {app }} / K_{\text {app }}+\left[\mathrm{H}^{+}\right]$, using the least squares method. After fitting to determine the best values of $P_{1}, P_{2}$, and $K_{\text {app }}$, this function was used to calculate the cytoplasmic $\mathrm{pH}$ from ratio determinations (25). The curves obtained were similar to those derived by measuring fluorescence in solution, and to results reported in previous studies with other cells $(22,26,27)$.

Role of intracellular bicarbonate. The effect of bicarbonate efflux on intracellular $\mathrm{pH}$ was determined by incubating dye-loaded osteoclasts in Hepes-buffered saline with bicarbonate for $20 \mathrm{~min}$ at $37^{\circ} \mathrm{C}$, and then transferring them into Hepes-buffered saline without bicarbonate while monitoring fluorescence ratios as indicated in Table I.

Role of extracellular sodium. Sodium free medium was prepared by replacing $\mathrm{Na}^{+}$isoosmotically with $\mathrm{N}$-methyl-D-glucamine and titrating the $\mathrm{pH}$ to 7.4 with $\mathrm{HCl}$. Washed osteoclasts loaded with dye were transferred to this medium, with or without $100 \mu \mathrm{M}$ amiloride, after 
preincubation in $140 \mathrm{mM} \mathrm{NaCl}$ and $10 \mathrm{mM}$ Hepes (pH 7.4) to stabilize their intracellular $\mathrm{pH}$. The effect of $\mathrm{HCO}_{3}^{-}$removal was tested by adding $25 \mathrm{mM}$ bicarbonate to the $\mathrm{NaCl} / \mathrm{Hepes}$ medium, monitoring cytoplasmic $\mathrm{pH}$ until a stable value was reached, and then transferring the cells to sodium-free medium without added bicarbonate. The cytoplasmic $\mathrm{pH}$ was then followed for an additional 20-30 min.

Measurement of cytoplasmic $\mathrm{pH}$ in chloride-free medium. Chloride-free medium was prepared by isotonically substituting Hepesbuffered sodium gluconate or sodium cyclamate for $\mathrm{NaCl}$ and adjusting the $\mathrm{pH}$ to 7.4 with $\mathrm{NaOH}$. After equilibrating 6-carboxyfluorescein-loaded cells in $\mathrm{NaCl} / \mathrm{Hepes}$ medium containing $25 \mathrm{mM}$ $\mathrm{NaHCO}_{3}$, the cells were transferred to chloride-free medium without bicarbonate and the cytoplasmic pH monitored for 20-30 min. Chloride replacement by either gluconate or cyclamate gave identical results in these experiments. The dependence of acidification on chloride concentration was determined by mixing appropriate volumes of the $\mathrm{NaCl} / \mathrm{Hepes}$ and chloride-free media to achieve the indicated chloride concentrations. The effects of inhibitors of $\mathrm{Cl}^{-} / \mathrm{HCO}_{3}^{-}$exchange were tested by transferring osteoclasts preincubated in $25 \mathrm{mM} \mathrm{HCO}_{3}^{-}$to medium without added bicarbonate but containing $100 \mu \mathrm{M} 4,4^{\prime}$-diisothiocyanatostilbene-2,2'-disulfonate (DIDS) or $100 \mu \mathrm{M}$ diphenylamine-2-carboxylate (DIPH). $10 \mu \mathrm{M}$ acetazolamide was used to assess the contribution of carbonic anhydrase to cytoplasmic alkalinization or acidification.

\section{Results}

Determination of cytoplasmic pH in osteoclasts. Fluorescence microscopy of dye-loaded osteoclasts revealed uniform staining of the cells with no apparent concentration of dye in intracellular organelles (Fig. 1). In addition, dye-labeled osteoclasts retained their normal morphology and remained attached to bone (not shown). Such cells, transferred to Hepes-buffered saline (pH 7.4), achieved a cytoplasmic $\mathrm{pH}$ of 7.05-7.15 within 10-15 min (Fig. 2) and, thereafter, exhibited a slow cytosolic acidification $(0.2 \mathrm{pH} \mathrm{U/h}$ or less).

Effect of bicarbonate on cytoplasmic pH. Transfer of 6-carboxyfluorescein-labeled osteoclasts into $25 \mathrm{mM}$ bicarbonate-

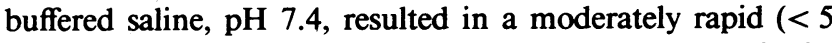
min) alkalinization of the cytoplasm to $\mathrm{pH} 7.25-7.50$ (Fig. 3). In bicarbonate buffer, the intracellular $\mathrm{pH}$ remained stable for 15-20 min but fell rapidly ( $<1 \mathrm{~min})$ to $6.7-6.8$ when the cells were returned to bicarbonate-free medium (a phenomenon not observed with comparably treated J774.1 macrophages or human skin fibroblasts). This acidification was followed by a slow recovery of the cytosolic pH to 7.0-7.1 over $20 \mathrm{~min}$ in the same buffer. The recovery, but not the initial acidification was inhibited by $2.5 \mathrm{mM} \mathrm{KCN}$ and $5 \mathrm{mM}$ deoxyglucose (Fig. 4).

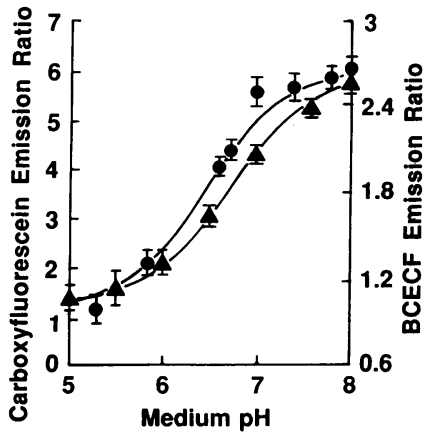

Figure 2. Calibration of fluorescence ratio with $\mathrm{pH}$ for BCECF-(๑) and 6-carboxyfluorescein-( $(\Delta)$ loaded osteoclasts. The cells were loaded as indicated in Table I and then transferred to a medium containing $130 \mathrm{mM} \mathrm{KCl}, 20 \mathrm{mM}$ $\mathrm{NaCl}, 5 \mathrm{mM}$ Hepes with 10 $\mu \mathrm{g} / \mathrm{ml}$ nigericin added (Methods). The pH of this medium was adjusted using acetic acid or ammonium hydroxide

to the indicated values and the fluorescence ratio was determined using the appropriate excitation wavelengths (Table I). The solid curves were then calculated as detailed in Methods $(n=10, \pm \mathrm{SD})$.

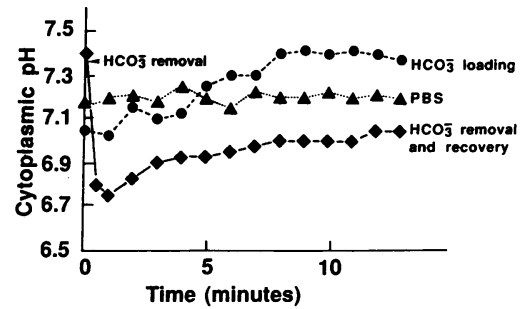

Figure 3. Effect of bicarbonate on intracellular pH. Representative $\mathrm{pH}$ recordings of 6-carboxyfluorescein-labeled osteoclasts showing an intracellular $\mathrm{pH}$ of $7.0-7.15$ in $\mathrm{pH} 7.4$ Hepes-buffered PBS ( $₫$ ). Transfer of cells to medium with $25 \mathrm{mM}$ bicarbonate added (pH 7.4) results in a slow alkalinization of the cytoplasm to $\mathrm{pH} 7.45(\bullet)$. When these $\mathrm{HCO}_{3}^{-}$ loaded cells are placed back in bicarbonate-free salt solution, they show rapid intracellular acidification to $\mathrm{pH} 6.75$, followed by a slow recovery to $\mathrm{pH} 7.05(\bullet)$. These results are representative of $\sim 20$ experiments done during these studies. When these experiments were used to calculate the SD, the resulting range was smaller than the symbols plotted on the graph and therefore is not shown in this case.

The cytoplasmic $\mathrm{pH}$ changes were simplified by the manner in which these experiments were done. We added sodium bicarbonate to our medium immediately before we used it in room air (nominal absence of $\mathrm{CO}_{2}$ ). This allowed us to observe the effect of bicarbonate movement on cytoplasmic $\mathrm{pH}$ without the complication of large fluxes of $\mathrm{CO}_{2}$ in or out of the cell. Therefore an initial acidification (due to diffusion of $\mathrm{CO}_{2}$ into the cytoplasm) was not observed or was very transient when cells were placed into bicarbonate-containing medium (14).

Effect of extracellular sodium on cytoplasmic pH. Fig. 5 shows that the fall in cytoplasmic $\mathrm{pH}$ initiated by bicarbonate removal was not affected when $N$-methyl-D-glucamine replaced sodium in the medium. Acidification was similarly unaffected when the sodium/proton exchange blocker amiloride $(100 \mu \mathrm{M})$ was added to the medium (not shown). In these experiments, osteoclasts were initially loaded with bicarbonate in the presence of sodium to limit the slow cytoplasmic acidification that occurs in Na-free solution. Acidification of this type is generally observed in cells that use $\mathrm{Na}^{+} / \mathrm{H}^{+}$exchange to export metabolic acid from their cytoplasm (29). In osteoclasts, the $\mathrm{pH}$ change associated with metabolic activity occurred slowly ( $\sim 0.2 \mathrm{pH}$ units/h) and, consequently, does not compromise measurements of the larger and more rapid $\mathrm{pH}$ changes initiated by bicarbonate removal.

Effect of extracellular chloride on cytoplasmic $p H$. The preceding observations demonstrate that avian osteoclasts express an anion transport system capable of altering cytoplasmic $\mathrm{pH}$. To demonstrate that $\mathrm{Cl}^{-} / \mathrm{HCO}_{3}^{-}$exchange is the major path-

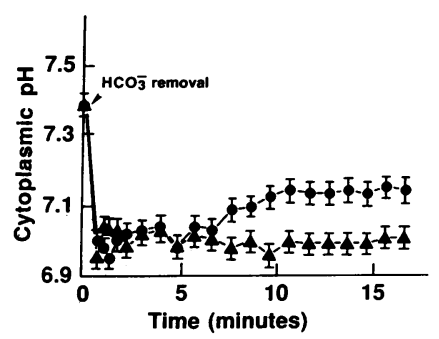

Figure 4. Effect of metabolic inhibitors on cytoplasmic acidification and recovery upon bicarbonate removal. Osteoclasts were incubated with $5 \mathrm{mM} 2-$ deoxyglucose and $2.5 \mathrm{mM}$ $\mathrm{KCN}$ for 20 min during equilibration with bicarbonate. There is no difference between control cells $(\bullet)$ and those

treated with $\mathrm{KCN}$ and 2-deoxyglucose ( $\Delta)$ in the cytoplasmic acidification which occurs when bicarbonate is removed. However, the recovery of cytoplasmic pH is blocked by the metabolic inhibitors. The error bars represent the range of $\mathbf{3 0}$ determinations at each time point in three separate experiments. 


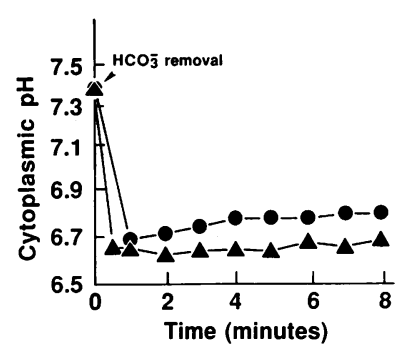

Figure 5. Effect of sodium removal on cytoplasmic acidification upon bicarbonate removal. The cytoplasmic acidification in sodium-free medium $(\Delta)$ is the same as in Hepes-buffered PBS $(\bullet)$. The cells were loaded with BCECF and then incubated in bicarbonate-containing media as described in Methods. At time 0 on

the figure, the cells were transferred to medium with $N$-methyl-D-glucamine replacing sodium and the cytoplasmic $\mathrm{pH}$ monitored spectrofluorometrically. The SDs were smaller than the point symbols and are therefore not shown.

way of alkaline equivalent export by active osteoclasts, we studied the effect of varying extracellular chloride on the osteoclast's ability to respond to a cytoplasmic alkaline load. Fig. $6 \mathrm{~A}$ shows the response of osteoclast cytoplasmic $\mathrm{pH}$ when extracellular chloride was isoosmotically replaced by $\mathrm{Na}$-cyclamate, in the nominal absence of extracellular bicarbonate. After chloride removal (closed circles) there was an increase of cytoplasmic $\mathrm{pH}$ from 6.9 to 7.3 , indicating an endogenous alkaline loading of the osteoclast that is compensated in the presence of $\mathrm{Cl}^{-}$. When the cells were returned to chloride-containing medium, the cytoplasmic $\mathrm{pH}$ immediately returned to its initial value. We also studied the response of avian osteoclasts to exogenous cytoplasmic base loading with ammonium chloride (Fig. $6 \mathrm{~B}$ ). When cells preequilibrated in the nominal absence of bicarbonate were transferred to chloride-free medium, we again saw a cytoplasmic alkalinization when $25 \mathrm{mM}$ $\mathrm{NaHCO}_{3}$ medium was added. A cytoplasmic alkaline load was then imposed on cells in sodium cyclamate (open circles) or on cells in normal medium (closed circles, Fig. $6 B$ ) by the addition of $50 \mathrm{mM} \mathrm{NH}_{4} \mathrm{Cl}$. When the ammonium chloride was washed away, the cells that had been incubated in low chloride medium $\left(50 \mathrm{mM} \mathrm{Cl}^{-}\right.$from $\mathrm{NH}_{4} \mathrm{Cl}$ ) rapidly returned to their initial cytoplasmic $\mathrm{pH}(6.8-6.9)$ but the cells in chloride-containing medium ( $190 \mathrm{mM}$ total $\mathrm{Cl}^{-}$) drop to a cytoplasmic $\mathrm{pH}$ of 6.55 and then recovered to 6.9 within $20 \mathrm{~min}$. This demonstrates a greater accumulation of acid $\left(\right.$ as $\left.\mathrm{NH}_{4}^{+}\right)$by the cells incubated in medium containing $170 \mathrm{mM}$ chloride.

We also determined the effect of extracellular chloride concentration on the cytoplasmic acidification that results when bicarbonate-equilibrated cells are transferred to medium with no added bicarbonate (Fig. 3). Fig. 7 (triangles) shows that when bicarbonate-loaded cells were transferred to chloridefree medium without bicarbonate, cytoplasmic $\mathrm{pH}$ remained relatively stable, at $7.25-7.50$ for 20-30 min. Furthermore, the rate and extent of acidification varied directly with medium $\mathrm{Cl}^{-}$concentration from 0 to $140 \mathrm{mM}$. Cytoplasmic acidification when bicarbonate was removed was 0.2 in $30 \mathrm{mM}$ chloride and 0.4 in $70 \mathrm{mM}$ chloride. The observation that $50 \mathrm{mM}$ $\mathrm{Cl}^{-}$(as $\mathrm{NH}_{4} \mathrm{Cl}$ ) thus did not permit significant compensation, for the alkaline loading in Fig. $6 B$ is probably due to ineffcient exchange at low chloride concentrations.

Effect of inhibitors of anion translocation on bicarbonateinduced acidification. Both DIDS, an inhibitor of anion transport $(20,30)$ and DIPH, a chloride channel blocker and inhibitor of $\mathrm{Cl}^{-} / \mathrm{HCO}_{3}^{-}$exchange $(31,32)$, significantly reduced the acidification associated with the transfer of osteoclasts to bicarbonate-free medium (Fig. 8). Importantly, inhibition by $100 \mu \mathrm{M}$ DIDS was completely and immediately reversed when
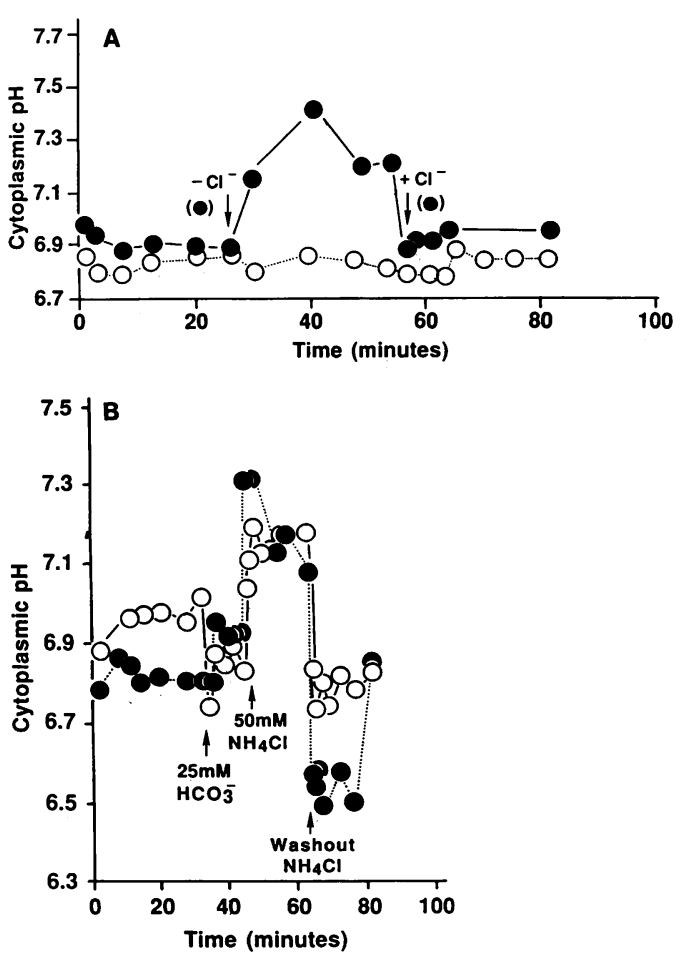

Figure 6. Role of extracellular chloride in cytoplasmic pH regulation. Osteoclasts were prepared on glass chips and loaded with BCECF as described before. In $A$, two glass chips containing osteoclasts were allowed to equilibrate in Hepes-buffered PBS, reaching a cytoplasmic $\mathrm{pH}$ of 6.8-6.9 with in $25 \mathrm{~min}$. At the first arrow one chip (•) was transferred to a medium containing Na-cyclamate isotonically replacing $\mathrm{NaCl}$ ( $\mathrm{pH} 7.4)$. After $\sim 40 \mathrm{~min}$ (second arrow) this chip was returned to Hepes-buffered PBS. In $B$, exposure to chloride-free medium was extended to include the addition of bicarbonate and ammonium chloride. Cells were first allowed to equilibrate in Hepesbuffered PBS (pH 7.4) and then one chip (o) was transferred to the Na-cyclamate buffer ( $\mathrm{pH} 7.4)$, while the other was washed with Hepes-buffered saline. At $30 \mathrm{~min}, 25 \mathrm{mM} \mathrm{NaCHO} \mathrm{O}_{3}$ was added to the medium bathing both chips ( first arrow). 10 min later $50 \mathrm{mM}$ $\mathrm{NH}_{4} \mathrm{Cl}$ was added to the medium bathing both chips. After $20 \mathrm{~min}$ exposure to $\mathrm{NH}_{4} \mathrm{Cl}$, both chips were returned to bicarbonate containing medium either with $(\bullet)$ or without $(0)$ chloride present. Cytoplasmic $\mathrm{pH}$ was observed for an additional $10 \mathrm{~min}$ in this buffer. $B$ compares the osteoclast's response to exogenous base loading in the presence of normal chloride concentration $(\bullet)$ or in medium with a reduced chloride concentration (0). The excessive cytoplasmic acidification upon removal of $\mathrm{NH}_{4} \mathrm{Cl}$ is a common response in cells that are able to compensate for base loading by ammonium chloride. The reduction of medium chloride clearly reduces the washout acidification in osteoclasts.

the cells were transferred to $\mathrm{NaCl} / \mathrm{Hepes}$, indicating that this dose was not toxic to the cells. Higher concentrations of DIDS $(200 \mu \mathrm{M})$ resulted in changes in cellular morphology and were therefore considered toxic. In contrast to the blocking activity of DIDS and DIPH, $10 \mu \mathrm{M}$ acetazolamide, a carbonic anhydrase inhibitor, had no effect on pH change (Fig. 8). This suggests a minimal role for carbonic anhydrase in either proton transport or $\mathrm{Cl}^{-} / \mathrm{HCO}_{3}^{-}$exchange.

Effect of time in culture on bicarbonate-induced cytoplasmic acidification. Osteoclasts maintained for periods up to $6 \mathrm{~d}$ in MEM with $10 \%$ FCS showed no discernable change in the resting cytoplasmic pH measured in Hepes-buffered PBS. However, such cells showed a steady diminution in their ca- 
Figure 7. Chloride dependence of cytoplasmic acidification. Cells were loaded with bicarbonate as previously described and then transferred to bicarbonate-free medium containing the indicated isotonic replacement of sodium gluconate for chloride. Each point represents the average of $10 \mathrm{pH}$ determinations. The SD was smaller than the point symbols and therefore is not plotted on this figure.

pacity to undergo cytoplasmic acidification when bicarbonate was removed from the medium as described above (Fig. 9).

\section{Discussion}

Bone resorption is necessary both for skeletal growth, remodeling, and in the regulation of ionized extracellular calcium levels (33). It has recently been established that bone resorption is accomplished by acidification of the extracellular microenvironment formed at the osteoclast-bone interface (3-6). To maintain an acid $\mathrm{pH}$ in the resorptive compartment during resorption, the osteoclast must continuously transport protons into that space. Solubilization of each mole of hydroxyapatite at $\mathrm{pH} \sim 5$ (4) consumes $\sim 6 \mathrm{~mol}$ of $\mathrm{H}^{+}$, and the buffering capacity of bone-derived collagen degradation fragments (12), may be substantial.

The presence of a pump capable of transferring protons to the resorption compartment (6) would impart an equal alkaline load on the cytoplasm of the osteoclast. Functionally, this is similar to the situation of the intercalated cell of the renal tubule, which secretes $\mathrm{H}^{+}$into the lumenal space using an ATP-dependent proton pump (16-18). These cells dispose of alkaline equivalents along their basolateral surfaces using $\mathrm{Cl}^{-} /$ $\mathrm{HCO}_{3}^{-}$exchange and are thereby able to maintain their cytoplasmic $\mathrm{pH}$ at physiologic values (17-19). We postulated that osteoclasts use a similar mechanism for $\mathrm{pH}$ homeostasis. To explore this postulate, osteoclasts were loaded with $\mathrm{pH}$-sensitive dyes, 6-carboxyfluorescein (22) or BCECF (26) and intracellular $\mathrm{pH}$ was monitored while electrolyte composition of the medium was systematically varied. These experiments showed that osteoclasts have a high capacity for $\mathrm{Cl}^{-} / \mathrm{HCO}_{3}^{-}$ exchange and that this exchange mechanism plays an important role in the regulation of cytoplasmic pH during bone resorption.

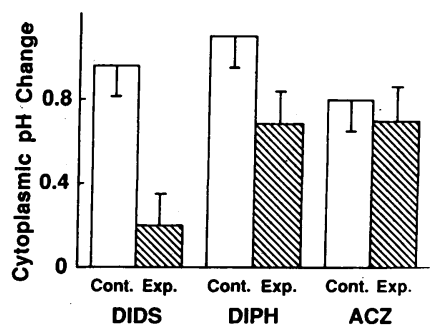

Figure 8. Effect of inhibitors of chloride channels and carbonic anhydrase on cytoplasmic acidification. Cells which had been $\mathrm{BCECF}$-labeled and $\mathrm{HCO}_{3}^{-}$-loaded cells were transferred to bicarbonate-free media in the presence or absence of $100 \mu \mathrm{M}$ DIDS, 100 $\mu \mathrm{M}$ DIPH, or $10 \mu \mathrm{M}$ acetazolamide. The anion exchange inhibitor, DIDS, and the chloride channel blocker, DIPH, reduce the cytoplasmic acidification, whereas the carbonic anhydrase blocker, acetazolamide, had no effect on cytoplasmic acidification. The differences in the extent of cytoplasmic acidification by the controls is due to the use of cultures at different days after isolation (see Fig. 8). The error bars represent the SD in three determinations for each inhibitor.

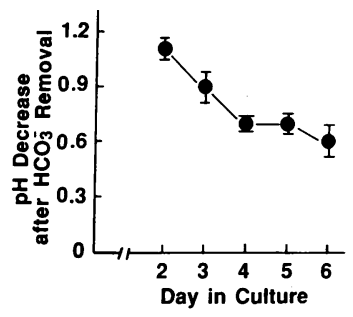

Figure 9. Cytoplasmic acidification and time of osteoclast culture. Osteoclasts showed a decrease in cytoplasmic acidification as the time in culture increased. These cells were loaded with BCECF and then exposed to bicarbonate and switched to bicarbonate-free media as described in Fig. 3 and Methods. In each case the extent of cytoplasmic acidification is

compared with cells having been in culture for the same time period but left in bicarbonate containing media. These results represent the average of three determinations for each time in culture and the bars indicate the SD of acidification which we observed.

Our initial observations involved assessing $\mathrm{pH}$ change initiated by transferring osteoclasts into bicarbonate-containing medium. Exposure to bicarbonate resulted in a slight alkalinization of the cytoplasm (stabilizing at pH 7.25-7.4), whereas transfer back to bicarbonate-free media initiated a sharp drop in intracellular pH (0.6-0.8 U) (Fig. 3). The alkalinization observed upon the addition of bicarbonate is consistent with $\mathrm{Cl}^{-}$movement out of the cells, against the existing chloride gradient, and the accumulation of $\mathrm{HCO}_{3}^{-}$in the cytoplasm. The much more rapid acidification that resulted when bicarbonate was removed from the medium occurred because, under these circumstances, both $\mathrm{Cl}^{-}$and $\mathrm{HCO}_{3}^{-}$gradients favored the efflux of bicarbonate from the cell. This rapid acidification was not affected by the presence of inhibitors of ATP production (2-deoxyglucose and cyanide, Fig. 4) or the replacement of sodium in the medium by $N$-methyl-D-glucamine (Fig. 5).

Although these observations indicate the presence of bicarbonate transport by the osteoclast, they do not indicate the mechanism of this transport or whether this process is important in the cytoplasmic pH homeostasis of active osteoclasts. To examine this aspect of our postulate, we exposed osteoclasts to medium containing reduced chloride and determined how this cell responded to both endogenous and exogenous alkaline loads. When active osteoclasts were placed in a chloride-free medium in the absence of added bicarbonate, there was a rise in cytoplasmic pH of 0.4-0.6 U (Fig. $6 \mathrm{~A}$ ). This change is consistent with the presence of endogenous alkaline loading of osteoclasts that are actively resorbing bone, which is corrected in a fashion requiring extracellular chloride. To better define this mechanism, osteoclasts were exposed to $50 \mathrm{mM}$ $\mathrm{NH}_{4} \mathrm{Cl}$ to alkalinize their cytoplasm (in medium containing bicarbonate, with or without cyclamate substitution for chloride), and then transferred to the same medium but without ammonium chloride. When ammonium chloride was removed, osteoclasts incubated in medium containing chloride hyperacidify and recover but osteoclasts incubated in cyclamate $\left(+50 \mathrm{~m} \mathrm{M} \mathrm{Cl}^{-}\right)$do not hyperacidify when $\mathrm{NH}_{4} \mathrm{Cl}$ is removed from the medium (Fig. $6 \mathrm{~B}$ ). Weak bases (such as $\mathrm{NH}_{4} \mathrm{Cl}$ ) distribute themselves across semipermeable membranes according to the $\mathrm{pH}$ on each side of the membrane. Cytoplasmic hyperacidification resulted because acid equivalents were transferred into the cytoplasm opposing the ammonium chloride-induced increase in cytoplasmic $\mathrm{pH}$. The transfer of acid equivalents into the osteoclast cytoplasm resulted in additional $\mathrm{NH}_{4}^{+}$accumulation in the osteoclast cytoplasm (28). When extracellular $\mathrm{NH}_{4} \mathrm{Cl}$ was removed, ammo- 
nia $\left(\mathrm{NH}_{3}\right)$ exited the cell, leaving behind the acid equivalents transferred there and producing hyperacidification. Therefore, the overshoot indicates that there was an attempted compensation for the alkaline load imparted by the $\mathrm{NH}_{4} \mathrm{Cl}$. Furthermore, because the overshoot only occurred in the presence of extracellular chloride $(>50 \mathrm{mM})$ we propose that chlorideanion exchange is required. This finding of a chloride dependent acid accumulation is further substantiated by experiments in which osteoclasts are transferred from bicarbonatecontaining to bicarbonate-free medium with varying concentrations of extracellular chloride. Under these circumstances, there is a clear, incremental chloride dependence in the rate of cytoplasmic acidification. No alteration in $\mathrm{pH}$ is seen in the absence of chloride but step-wise increases in acidification are observed at 30,70,120, and $140 \mathrm{mM}$ of anion (Fig. 7). These data also suggest that ammonium chloride induced hyperacidification (Fig. $6 \mathrm{~B}$ ) was not observed in the presence of $50 \mathrm{mM}$ chloride (added as $\mathrm{NH}_{4} \mathrm{Cl}$ ) because be-

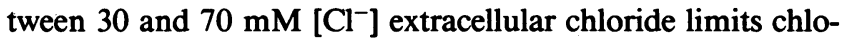
ride/bicarbonate exchange and at a reduced level of exchange hyperacidification could not be observed when $\mathrm{NH}_{4} \mathrm{Cl}$ was removed. The chloride concentration dependence we found is similar to that observed in other systems involving $\mathrm{Cl}^{-} / \mathrm{HCO}_{3}^{-}$ exchange (14).

We used pharmacologic agents that block chloride transport to support our conclusion that osteoclast cytoplasmic acidification resulted from chloride-dependent bicarbonate transport. Fig. 8 shows inhibition of cytoplasmic acidification by an inhibitor of anion exchange, DIDS $(30,31)$, and a chloride channel blocker, DIPH (32). DIPH has recently been reported to inhibit $\mathrm{Cl}^{-} / \mathrm{HCO}_{3}^{-}$exchange in necturus gall bladder epithelium (33). In contrast, neither the removal of extracellular sodium nor metabolic inhibitors affected cytoplasmic acidification upon transfer out of bicarbonate-containing medium (Figs. 4 and 5). These observations are consistent with a Na-independent chloride/bicarbonate exchange.

Acetazolamide, a potent inhibitor of carbonic anhydrase type II, had no effect on acidification due to $\mathrm{Cl}^{-} / \mathrm{HCO}_{3}^{-}$exchange (Fig. 8). The importance of carbonic anhydrase in bone resorption is uncertain, although osteoclasts definitely contain carbonic anhydrase type II (34), and in one syndrome, carbonic anhydrase type II is absent from patients who also have osteopetrosis (35). However, there are no reports of osteopetrosis, skeletal abnormalities, or hypocalcemia due to acetazolamide therapy in glaucoma patients, who are routinely treated for long periods with doses of acetazolamide that effectively block this enzyme. Furthermore, attempts to block bone resorption by isolated osteoclasts using acetazolamide have been unsuccessful (unpublished observations), although by using very high doses $\left(10^{-4} \mathrm{M}\right)$ of acetazolamide, effects on bone resorption have been shown (36). It remains to be seen whether deficiency of carbonic anhydrase type II limits osteoclast function under some circumstances; our results thus indicate that it does not affect the acidification of the osteoclast's cytoplasm by $\mathrm{Cl}^{-} / \mathrm{HCO}_{3}^{-}$exchange.

The functional polarization of the osteoclast by this acidic bone resorption compartment at the cell-bone interface, and our observation of active $\mathrm{Cl}^{-} / \mathrm{HCO}_{3}^{-}$exchange by these same cells, is reminiscent of the mechanism for acid secretion observed in renal epithelial cells (7). We therefore propose that osteoclasts neutralize the alkaline equivalents produced during acidification of the bone resorbing compartment by $\mathrm{Cl}^{-} /$
$\mathrm{HCO}_{3}^{-}$exchange. Our observations indicate that the $\mathrm{Cl}^{-} /$ $\mathrm{HCO}_{3}^{-}$exchange in osteoclasts is $\mathrm{Na}$-independent and that it can be blocked by inhibitors of anion exchange and chloride channels. During active bone resorption, removal of bicarbonate from the osteoclast cytoplasm would balance the active secretion of protons into the bone-resorbing compartment and thus maintain a normal cytoplasmic $\mathrm{pH}$. We have also observed that the $\mathrm{Cl}^{-} / \mathrm{HCO}_{3}^{-}$-dependent acidification declines with time of osteoclasts in culture (Fig. 9). This change correlates with the disappearance of the ultrastructural feature associated with the osteoclast's bone-degrading capacity, the ruffled membrane (unpublished data). The osteoclast's $\mathrm{Cl}^{-} /$ $\mathrm{HCO}_{3}^{-}$exchange thus may be regulated coincidentally with other components of the bone-resorbing apparatus.

\section{Acknowledgments}

This work was supported by National Institutes of Health grants AM-32788 and AR-01631, and a grant from The Shriner's Hospital for Crippled Children (St. Louis Unit).

\section{References}

1. Marchisio, P. E., D. Cirillo, L. Naldini, H. V. Primavera, A. Teti, A. Zambonin-Zallone. 1984. Cell substratum interaction of cultured avain osteoclasts is mediated by specific ahesion structures. $J$. Cell Biol. 99:1696-1705.

2. Marchisio, P. E., D. Cirillo, A. Teti, A. Zambonin-Zallone, G. Tarone. 1987. Rous sarcoma virus transformed fibroblasts and cells of monocytic origin display a pecular dot-like organization of cytoskeletal proteins involved in microfilament-membrane interactions. Exp. Cell. Res. 169:202-214.

3. Cretin, A. 1951. Contribution histochimique a l'étude de la construction et de la destruction osseuse. Presse Med. 60:1240-1241.

4. Fallon, M. D. 1984. Bone resorbing fluid from osteoclasts is acidic: an in vitro micropuncture study. In Endocrine Control of Bone and Calcium Mtabolism. Vol. 8A. C. V. Cohn, T. Fujita, J. T. Potts, Jr., and R. V. Talmadge, editors. Elsevier Science Publishers, Amsterdam. 144-146.

5. Baron, R., L. Neff, D. Louvard, and P. J. Courtoy. 1985. Cellmediated extracellular acidification and bone resorption: evidence for a low $\mathrm{pH}$ in resorbing lacunae and localization of a $100-\mathrm{kD}$ lysosomal membrane protein at the osteoclast ruffled border. J. Cell Biol. 101:2210-2222.

6. Ghiselli, R., H. Blair, S. Teitelbaum, and S. Gluck. 1987. Identification of osteoclast proton pump. J. Bone Min. Res. 275:25. (Abstr.).

7. Doty, S. B., and B. H. Schofield. 1972. Electron microscopic localization of hydrolytic enzymes in osteoclasts. Histochemie. 4:245258.

8. Gothlin, G., and J. L. E. Ericsson. 1971. Fine structural localization of acid phosphomonoesterase in the brush border region of osteoclasts. Histochemie. 28:337-344.

9. Lucht, V. 1971. Acid phosphatase of osteoclasts demonstrated by electron microscopic histochemistry. Histochemie. 28:103-117.

10. Vaes, G. 1968. On the mechanisms of bone resorption: the action of parathyroid hormone on the excretion and synthesis of lysosomal enzymes and on the extracellular release of acid by bone cells. $J$. Cell Biol. 39:676-697.

11. Eilon, G., and L. G. Raisz. 1978. Comparison of the effects of stimulators on inhibitors of resorption on the release of lysosomal enzymes and radioactive calcium from fetal bone in organ cultures. Endocrinology. 103:1969-1975.

12. Blair, H. C., A. J. Kahn, E. C. Crouch, J. J. Jeffrey, and S. L. Teitelbaum. 1986. Isolated osteoclasts resorb the organic and inorganic components of bone. J. Cell Biol. 102:1164-1172. 
13. Zambonin-Zallone, A., A. Teti, and M. V. Primavera. 1982. Isolated osteoclasts in primary culture: first observations on structure and survival in culture media. Anat. Embryol. 165:405-415.

14. Zeidel, M. L., P. Silva, and J. L. Seifer. 1986. Intracellular pH regulation and proton transport by rabbit renal medually collecting cells: role of plasma membrane $\mathrm{H}^{+}-$ATPase. J. Clin. Invest. 77:113120.

15. Gluck, S., and Q. Al-Awquati. 1984. An electrogenic proton translocating ATPase from bovine kidney medulla. J. Clin. Invest. 73:1704-1710.

16. Steinmetz, P. R., and O. S. Anderson. 1982. Electrogenic proton transport in epithelial membranes. Membr. Biol. 65:155-174.

17. Lombard, W. E., J. P. Kokko, and H. R. Jacobson. 1983 Bicarbonate transport in cortical and outer medullary collecting tubules. Am. J. Physiol. 224:F289-F296.

18. Stone, D. K., D. W. Seldin, J. P. Kokko, and H. R. Jacobson. 1983. Anion dependence of rabbit medullary collecting duct acidification. J. Clin. Invest. 71:1505-1508.

19. Koeppen, B. M. 1985. Conductive properties of the rabbit outer medullary collecting duct: inner stripe. Am. J. Physiol. 248:F500F506.

20. Zeidel, M. L., P. Silva, and J. L. Seifter. 1986. Intracellular pH regulation in rabbit renal medullary collecting duct cells. Role of chloride-bicarbonate exchange. J. Clin. Invest. 77:1682-1688.

21. Teitelbaum, S. L., C. C. Stewart, and A. J. Kahn. 1979. Rodent peritoneal macrophages as bone resorbing cells. Calcif. Tissue Int. 27:255-261.

22. Thomas, J. A., R. N. Buchsbaum, A. Simmiek, and E. Recker. 1979. Intracellular pH measurements to Ehrlich ascites tumor cells utilizing spectroscopic probes generated in situ. Biochemistry. 18:2210-2218.

23. Okhuma, S., and B. Poole. 1978. Fluorescence probe measurement of the intralysosomal $\mathrm{pH}$ in living cells and the perturbation of pH by various agents. Proc. Natl. Acad. Sci. USA. 75:3327-3331.

24. Krogstad, D. J., and P. H. Schlesinger. 1986. A perspective on antimalarial action: effects of weak bases on Plasmodium falciparum. Biochem. J. 35:547-552.

25. Krogstad, D. J., P. H. Schlesinger, and I. Y. Gluzman. 1985.
Antimalarials increase vesicle $\mathrm{pH}$ in Plasmodium falciparum. J. Cell Biol. 101:2203-2209.

26. Rink, T. J., R. Y. Tsien, and T. Possan. 1982. Cytoplasmic pH and free magnesium in lymphocytes. J. Cell Biol. 95:181-196.

27. Jamieson, G. A., Jr., W. A. Frazier, and P. H. Schlesinger. 1984. Transient increase in intracellular $\mathrm{pH}$ during Dictyostelium discoideum differentiation. J. Cell Biol. 99:1883-1887.

28. Boron, W. P. and P. De Weer. 1976. Intracellular pH transients in squid giant axons caused by $\mathrm{CO}_{2}, \mathrm{NH}_{3}$, and metabolic inhibitors. $J$. Gen. Physiol. 67:91-112.

29. Rothenberg, P., L. Glaser, L. Schlesinger, and D. Cassel. 1983. Activation of $\mathrm{Na}^{+} / \mathrm{H}^{+}$exchange by epidermal growth factor elevates intracellular pH in A431 cells. J. Biol. Chem. 258:12644-12653.

30. Burkhardt, B-Ch., A. C. Cassola, and E. Fromter. 1984. Electrophysiologic analysis of bicarbonate permeation across the peritubular cell membrane of the kidney proximal tubule. II. Exclusion of $\mathrm{HCO}_{3}^{-}$ effects on other ion permeability and of coupled electroneutral $\mathrm{HCO}_{3}^{-}$ transport. Pfleuger's Arch. Eur. J. Physiol. 401:43-51.

31. Distefano, A., M. Whitney, E. Schletter, H. J. Lang, H. Engleit, and R. Greger. 1985. Diphenylamine-2-carboxylate, a blocker of the $\mathrm{Cl}^{-}$conductive pathway of $\mathrm{Cl}^{-}$transporting epithelium. Pfleuger's Arch. Eur. J. Physiol. 405:95-100.

32. Reuss, L., J. L. Constantin, and J. E. Bazile. 1987. Diphenylamine-2-carboxylate blocks $\mathrm{Cl}^{-} / \mathrm{HCO}_{3}$ exchange in Necturus gall bladder epithelium. Am. J. Physiol. 253:C79-C89.

33. Raisz, L. G. 1970. Physiological and pharmacological regulation of bone resorption. Semin. Med. Beth Israel Hosp. 282:909-916.

34. Gay, C. V., M. B. Ito, and H. Schraer. 1983. Carbonic anhydrase activity in isolated osteoclasts. Metab. Bone Dis. Relat. Res. 5:33-39.

35. Sly, W. S., D. Hewett-Emmett, M. P. Whyte, L. Yu YaShiough, and R. E. Tashian. 1983. Carbonic anhydrase Type II deficiency identified as the primary defect in the autosomal recessive syndrome of osteoporosis with renal tubular acidosis and cerebral calcification. Proc. Natl. Acad. Sci. USA. 80:2752-2756.

36. Hall, G. E., and A. D. Kenny. 1985. Role of carbonic anhydrase in bone resorption induced by 1,25-dihydroxy vitamin $\mathrm{D}$ in vitro. Calcif. Tissue Int. 37:134-142. 